
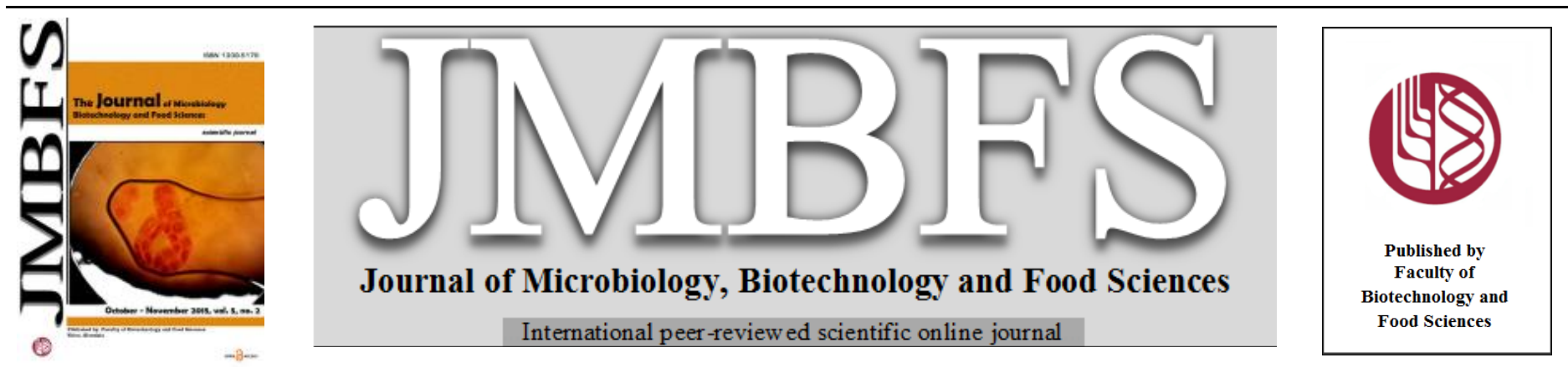

\title{
EFFECT OF DRYING METHODS ON CONTENT OF SOME NATURAL PIGMENTS IN URTICA DIOICA L. AND MELISSA OFFICINALIS L.
}

\author{
Lenka Droštinová, Jana Braniša, Dominika Bončíková, Klaudia Jomová
}

Address(es): prof. RNDr. PhD. Klaudia Jomová,

${ }^{1}$ Constantine the Philosopher University, Faculty of Natural Sciences, Department of Chemistry, Tr. A. Hlinku 1, 94974 Nitra, Slovak Republic, +421 376408656.

*Corresponding author: lenka.drostinova@ukf.sk

doi: 10.15414/jmbfs.2015.5.2.182-185

\section{ARTICLE INFO}

Received 18. 4. 2015

Revised 28. 8. 2015

Accepted 2. 9. 2015

Published 1. 10. 2015

Regular article open $\partial$ access

\begin{abstract}
Medicinal plants are usually marketed to the public in a dried form and in this form they can also be used for the needs of the pharmaceutical industry. Since the drying process can affect chemical changes in the plants several drying methods and conditions have been tested to preserve the quality and quantity of biologically active components. The objective of this study was to investigate the effect of convection oven drying at $25^{\circ} \mathrm{C} \pm 1{ }^{\circ} \mathrm{C}$ for 65 hours, microwave oven drying at $800 \mathrm{~W}$ for 45 seconds, and air drying with sun exposure at $25^{\circ} \mathrm{C} \pm 1{ }^{\circ} \mathrm{C}$ for 65 hours on the content of chlorophylls and carotenoids in leaves of two medicinal plants. The plants selected were stinging nettle (Urtica dioica $\mathrm{L}$.) and lemon balm (Melissa officinalis L.). The content of the natural pigments was investigated in the prepared extracts by the UV-VIS spectrophotometric method. Results showed higher content of pigments in Melissa officinalis when microwave drying procedure was applied compared to the oven dried samples and the sun dried samples (air dried with sun exposure) but a significant difference was only observed in the content of chlorophyll $b$. In Urtica dioica the air drying technique with sun exposure can be considered to be a more suitable drying procedure which preserves a higher amount of all pigments. Sun dried Urtica dioica samples had significantly higher chlorophylls and carotenoids content compared to the oven dried and microwave dried samples. In general, air drying with sun exposure seems to be the most suitable drying method in terms of preservation of pigments under study. This technique represents the simplest and most energy efficient drying procedure.
\end{abstract}

Keywords: Medicinal plants, chlorophylls, carotenoids, drying

\section{INTRODUCTION}

Medicinal plants have found many industrial uses, especially in the pharmaceutical and food industry, as well as in cosmetics. In pharmaceuticals, plant extracts are especially relevant due to the use of their active substances for medicine development (Rocha et al., 2011). Compounds studied in herbs are essential oil components, as well as the natural pigments such as flavonoids, chlorophylls, and carotenoids.

Chlorophylls and carotenoids are an important group of primary metabolites with a unique role in the process of photosynthesis. Carotenoids are yellow, orange, and red pigments. Chlorophylls are responsible for the green color of fruits and vegetables (Koca et al., 2007). These natural pigments are endowed with antioxidant activity (Sharafzadeh, Aliazadeh, 2011). Dietary carotenoid intake from vegetable and fruit sources has been correlated with a reduced cancer risk (Rock, 2003). Some studies indicate that chlorophylls may have some anticarcinogenic potential (Hojnik et al., 2007). For commercial purposes the chlorophyll is extracted for use as a green coloring agent in food and medicine (Guil-Guerrero et al., 2003). The main component of chlorophyll extract is chlorophyll $a(\mathrm{Chl} a)$ which is in the approximate ratio $3: 1$ to chlorophyll $b(\mathrm{Chl}$ b), (Hojnik et al., 2007). In the chlorophyll extract a certain amount of carotene pigments are also present.

Medicinal plants are usually used either in fresh form or in dried form. People dry herbs in order to keep them for future use. The process of drying should provide a rapid reduction in the moisture content without affecting the quality of the active ingredients of medicinal plants. During drying, enzymatic processes in fresh plant tissues may lead to significant changes in the composition of bioactive constituents of herbs (Puranik et al., 2012). Natural pigments such as carotenoids, chlorophylls, and flavonoids are susceptible to degradation during processing. Unsaturated chemical structure is susceptible to degradation factors such as oxidation.

Numerous studies deal with the influence of the drying procedure on the amount of pigments as well as other active ingredients. The results show that various drying methods differ in their effect (Puranik et al., 2012; Abascal et al., 2005; Komes et al., 2011; Rocha et al., 2011). The results depend on the conditions of drying method used, sample processing, as well as pigment extraction. Drying air temperatures between 50 and $60{ }^{\circ} \mathrm{C}$ appear to be feasible for drying a large number of medicinal plants (Rocha et al., 2011). Much research has been done with microwave drying procedure which reduces drying time. However, more data are required on the effect of the microwave drying on the quality and quantity of bioactive substances. Medicinal plants are often freeze dried and in such form used for research studies or marketed to the public (Abascal $\boldsymbol{e t}$ al., 2005). There exist contradictory facts regarding the effect of freeze drying method on the composition of biologically active substances but more systematic research is needed, as well. In common domestic conditions, natural drying in the sun or in the shade is widely used because of lower costs. This drying process is applicable for small quantities of herbs but mass production indispensably requires the use of technical devices.

The drying process is basically defined as the decreasing of plant moisture content aimed at preventing enzymatic and microbial activity, and consequently preserving the product for prolonged expiration time (Rocha et al., 2011). From another point of view the drying process may contribute to a regular supply and facilitate the marketing of plants, because the drying results in reduction of the weight and volume of the plant with positive consequences for transport and storage. Therefore, the drying is considered as a critical factor for the postharvest management and the merchantability of herbs (Oprahanides et al. 2013). Drying of herbs must meet several requirements regarding the moisture content and microbial count, as well as minimum quality reduction in terms of active ingredients, colour, flavour and aroma (Oztekin and Martinov, 2007).

In the present study we investigated the effect of three different drying methods (convection oven drying, microwave drying, and air drying in the sun) on the content of chlorophylls and carotenoids in leaves of the two medicinal plants Urtica dioica L. and Mellisa officinalis L. The aim was to find the most suitable drying method in terms of preservation of pigments content. The results obtained in a laboratory may provide recommendations for the selection of the drying method for plants under study. 


\section{MATERIAL AND METHODS}

Chemicals

All reagents used in the study were purchased from Centralchem (Slovakia) and were of analytical grade purity.

\section{Drying methods}

Herbs of lemon balm (Melissa officinalis L.) and stinging nettle (Urtica dioica L.) were manually collected from a private garden in Nitra region, West of Slovakia in June 2014. Leaves were carefully separated from the stems and dried on the same day by the three drying methods: convection oven drying (CD), microwave drying (MD), and air drying with sun exposure (SUD). For each drying method, $40 \mathrm{~g}$ of fresh leaves was used.

The conditions of dehydration were as follows:

1. Convection oven drying at $25^{\circ} \mathrm{C} \pm 1{ }^{\circ} \mathrm{C}$ for 65 hours (Binder ED115, Germany).

2. Microwave oven drying at $800 \mathrm{~W}$ for 45 seconds in three 15 second periods of heating interrupted by two 20 second pauses (GNIS AKL 535). During each pause single layer blotters placed at the bottom and at the top of the sample were removed and replaced by new ones.

3. Air drying with sun exposure for 65 hours at room temperature (mean temperature $25^{\circ} \mathrm{C}$ ).

The dehydration processes were conducted until the moisture content of dried medical herbs was below $14 \%$. The dry samples were homogenized in mortar and sieved on a mesh with $2 \mathrm{~mm}$ perforations. Each dehydrating procedure was carried out in four replicates. Before analysis, the samples were stored in a hermetic package in the dark at $4{ }^{\circ} \mathrm{C}$

\section{Determination of Chlorophyll $a$, Chlorophyll $b$ and Carotenoids}

Chl $a$, Chl $b$ and total carotenoids were determined by the method of Yang $\boldsymbol{e t ~ a l}$. (1998). Approximately $10 \mathrm{mg}$ of each dry sample was homogenized (IKAWERKE T10 Basic) with $10 \mathrm{ml}$ of acetone-water mixture (4:1) for 2 minutes to uniform mass. Samples were maintained in an ice-water bath to prevent overheating of the samples. The homogenates were centrifuged (Eppendorf Centrifuge 5804R, Germany) at $5000 \mathrm{rpm}$ for 10 minutes at $20{ }^{\circ} \mathrm{C}$. The absorbance spectrum of each supernatant was measured and the absorption maxima were read at $663.6 \mathrm{~nm}$ for Chl $a, 646.6 \mathrm{~nm}$ for Chl $b$ and $440.5 \mathrm{~nm}$ for carotenoids (UV/VIS spectrophotometer Cary $50 \mathrm{Scan}$ ). Contents of Chl $a$, Chl $b$ and carotenoids were calculated from the following equations:

$$
\begin{aligned}
& \text { Chlorophyll a }(\mu \mathrm{g} / \mathrm{ml})=12.25 A_{663,6}-2.25 A_{646,6} \\
& \text { Chlorophyll } b(\mu \mathrm{g} / \mathrm{ml})=20.31 A_{646,6}-4.91 A_{663,6}
\end{aligned}
$$$$
\text { Carotenoids }(\mu \mathrm{g} / \mathrm{ml})=4.69 A_{440,5}-0.267(\text { Chl } a+\text { Chl b }) \text {, }
$$

where $\mathrm{A}=$ absorbance. The same procedure was performed for each sample. The results were expressed as milligrams per gram of dried sample weight.

\section{Statistical Analysis}

All measurements were carried out for four independent experiments $(n=4)$ and the results are expressed as mean values \pm standard deviation (SD). The data were statistically analysed for significance of the differences using a common procedure based on calculating Student's t criterion according to formula:

$$
t=\frac{\left(\bar{x}_{A}-\bar{x}_{B}\right) \cdot \sqrt{n-1}}{\sqrt{s_{A}^{2}+s_{B}^{2}}}
$$

and comparing calculated $t$ with critical $t_{c r i t,(\mathrm{n}=4)}=3.182$, where $x_{A}$ and $x_{B}$ are arithmetic averages of the two sets under consideration, $s_{A}$ and $s_{B}$ are relating standard deviations and $\mathrm{n}$ is number of parallel experiments.

\section{RESULTS AND DISCUSSION}

Drying is one of the most common ways of post-harvest processing of medicinal herbs which may significantly affect the quality and quantity of the biologically active components (Rocha et al., 2011). Several studies have shown fluctuations of bioactive components after drying procedures. In our study we have determined the content of natural pigments (chlorophyll $a$, chlorophyll $b$, and carotenoids) in herbs ( $M$. officinalis, $U$. dioica) dried by using three different dehydrating processes. The drying conditions were optimized and selected after conducting trials performed to achieve the above mentioned level of moisture. Under these conditions the leaves of the herbs were brittle and no visible changes, such as dark spots, were observed.

According to the results shown in Table 1, the Chl $a$ content in M. officinalis varied from $5.67 \mathrm{mg} / \mathrm{g}$ (SUD) to $5.81 \mathrm{mg} / \mathrm{g}$ (MD). Content of Chl $b$ compared to Chl $a$ content was as expected lower in the range from $2.02 \mathrm{mg} / \mathrm{g}$ (SUD) to 2.99 $\mathrm{mg} / \mathrm{g}$ (MD). Content of carotenoids ranged from $1.20 \mathrm{mg} / \mathrm{g}$ (CD) to $1.39 \mathrm{mg} / \mathrm{g}$ (MD).

For M. officinalis the microwave drying seems to be the better dehydrating process to preserve the content of both chlorophylls and carotenoids. To confirm our observation, all results were statistically tested for conformity with regard to the drying methods (Table 2). The results of the mutual comparison of the drying techniques showed only significantly higher content of chlorophyll $b$ when the microwave drying procedure was applied compared to oven dried samples and sun dried samples (Table 2). As it can be seen in Table 2, no other significant differences were observed in the pigment content of $M$. officinalis.

Dermelj et al. (1995) and Divya et al. (2012) reported the effect of both the microwave treatment drying time and power of microwave on the total chlorophyll content. The higher energy power of microwave drying made the drying process faster but contributed more significantly to the loss of the active compounds than a smaller energy input (Dermelj et al., 1995). During trials conducted to optimize the microwave drying conditions we focused on reducing of the drying time. Under conditions used in our work (short interrupted time intervals at high power of microwave) the yields of all pigments in leaves of $M$ officinalis were higher compared to other applied techniques but they did not reach the statistically significant differences (besides the Chl $b$ content). For these conditions no detectable visual changes on the leaves were observed. If a longer time of microwave drying was used we observed dark spots on the leaves unevenly spread. This could be associated with the inhomogeneity of therma field that may lead to a too high temperature and overheating in some parts of the sample (mainly at the edges). This is the main disadvantage of microwave drying technique (Nijhuis et al., 1998).

Komes et al. (2011) evaluated the effect of three drying techniques on the content of carotenoids, chlorophylls and phenolic compounds in lemon balm (Melissa officinalis L.), as well as in marigold (Calendula officinalis L.) and borage (Borago officinalis L) all traditionally used medicinal plants. Besides microwave drying, the authors used the freeze drying and the air-drying at room temperature in the dark. Results of their study showed the highest content of carotenoids and chlorophylls in freeze dried plants, when compared to air-drying at room temperature in the dark and microwave dried plants. The microwave drying resulted in a significant degradation of all bioactive substances in all examined plants compared to freeze drying and air drying.

Table 1 Content of chlorophylls and carotenoids (mg/g dry weight) in leaves of Melissa officinalis and Urtica dioica dried using different drying methods The results are expressed as mean $\pm \mathrm{SD}(\mathrm{n}=4)$.

\begin{tabular}{lccc}
\multicolumn{5}{l}{ Melissa officinalis } & & \\
\hline \multicolumn{7}{c}{ Chlorophyll $\boldsymbol{a}$} & Chlorophyll $\boldsymbol{b}$ & Carotenoids \\
\hline CD & $5.77 \pm 0.19$ & $2.15 \pm 0.17$ & $1.20 \pm 0.24$ \\
MD & $\mathbf{5 . 8 1} \pm \mathbf{0 . 2 6}$ & $\mathbf{2 . 9 9} \pm \mathbf{0 . 1 9}$ & $\mathbf{1 . 3 9} \pm \mathbf{0 . 0 9}$ \\
SUD & $5.67 \pm 0.09$ & $2.02 \pm 0.02$ & $1.36 \pm 0.21$ \\
\hline & & & \\
Urtica dioica & & Chlorophyll $\boldsymbol{b}$ & Carotenoids \\
\hline & Chlorophyll $\boldsymbol{a}$ & $2.71 \pm 0.12$ & $1.53 \pm 0.07$ \\
CD & $7.04 \pm 0.09$ & $2.26 \pm 0.15$ & $1.68 \pm 0.07$ \\
MD & $6.65 \pm 0.51$ & $\mathbf{3 . 0 4} \pm \mathbf{0 . 1 3}$ & $\mathbf{1 . 8 3} \pm \mathbf{0 . 1 0}$ \\
SUD & $\mathbf{8 . 1 5} \pm \mathbf{0 . 3 8}$ &
\end{tabular}

In contrast to the lemon balm (M. officinalis) in $U$. dioica the air drying technique with sun exposure (SUD) can be considered to be the more suitable drying procedure which preserves the higher amount of all pigments under study (Table 1 ). The convection oven drying and microwave drying of $U$. dioica leaves gave the Chl $a$ a consistent content $(7.04 \mathrm{mg} / \mathrm{g} ; 6.65 \mathrm{mg} / \mathrm{g}$ ), while the value for air drying with sun exposure appeared as a higher value $(8.15 \mathrm{mg} / \mathrm{g})$. The Chl $b$ showed different results for each drying procedure and the highest content was observed using air drying with sun exposure $(3.04 \mathrm{mg} / \mathrm{g})$. In terms of carotenoid 
content the highest amount was also preserved by using air drying $(1.83 \mathrm{mg} / \mathrm{g})$ followed by microwave drying $(1.68 \mathrm{mg} / \mathrm{g})$ and convection oven drying $(1.53$ $\mathrm{mg} / \mathrm{g}$ ).

Table 2 shows the statistical significant differences in the content of pigments in $U$. dioica samples dried by the different techniques. Sun dried $U$. dioica samples
(SUD) had significantly higher chlorophyll and carotenoid content compared to oven dried and microwave dried samples. Significant differences in the content of chlorophyll $a$ and carotenoids were not observed between the oven drying and microwave drying methods in $U$. dioica samples.

Table 2 Statistical testing of conformity of different drying method effect on the content of pigments in Melissa officinalis and Urtica dioica. Student's criterion t calculated; $\mathrm{t}_{\text {crit }(\mathrm{n}=4)}=3.182, \alpha=0.05$.

Calculated t-criterion for pair compared

\begin{tabular}{lc|c|c|c|c|c|c|c|c}
\cline { 2 - 8 } & \multicolumn{3}{c}{ Chlorophyll $\boldsymbol{a}$} & \multicolumn{3}{c|}{ Chlorophyll $\boldsymbol{b}$} & \multicolumn{2}{c}{ Carotenoids } \\
\cline { 2 - 9 } & CD-MD & CD-SUD & MD-SUD & CD-MD & CD-SUD & MD-SUD & CD-MD & CD-SUD & MD-SUD \\
\hline Melissa officinalis & 0.26 & 1.60 & 0.88 & $5.71^{*}$ & 1.32 & $8.80^{*}$ & 1.38 & 0.87 & 0.23 \\
\hline Urtica dioica & 1.30 & $4.93^{*}$ & $4.08^{*}$ & $4.06^{*}$ & $3.23^{*}$ & $6.82^{*}$ & 2.62 & $7.42^{*}$ & $3.36^{*}$ \\
\hline
\end{tabular}

Legend: $\mathrm{CD}$ - convection oven drying, $\mathrm{MD}$ - microwave drying, $\mathrm{SUD}$ - air drying with sun exposure, $(*)$ statistically significant difference $\left(\mathrm{t}>\mathrm{t}_{\mathrm{krit}} \mathrm{n}=4\right)$

The observed results imply that the effect of drying techniques on the content of the studied pigments did not indicate unambiguous relations. It is generally accepted that the different drying techniques affect different pigments in a variety of ways and that the dehydration process results in the qualitative and quantitative changes in dried plants. The results obtained by Kamel et al. (2013) have shown that all methods of drying used (air drying, oven drying, microwave drying) significantly decreased the yield of carotenoids in the edible parts of leafy vegetables; the greatest reduction was observed using microwave drying method and less effect was observed using air drying. On the other hand, in the samples of bush tea dried by different methods (air, freeze, shade, and oven drying) no significant differences were observed in the content of carotenoids, but a higher amount of chlorophyll in freeze and shade dried samples was observed when compared to sun and oven dried samples (Mudau and Ngezimana, 2014). One should bear in mind that a variability of plants tested, as well as a great variability of both the methods and conditions of drying make comparison of results more difficult.

Based on our results we can recommend, in terms of chlorophyll and carotenoid preservation, that the most convenient drying procedure for $M$. officinalis is the microwave drying (MD) and for $U$. dioica it is the air drying with sun exposure (SUD).

The SUD represents the simplest method of drying which was performed under laboratory conditions in well ventilated space out of direct sunlight to avoid intensive solar radiation that adversely affects quality of dried herbs. This may explain the higher yields of studied pigments in $U$. dioica and statistically nonsignificant differences in $M$. officinalis for Chl $a$ and carotenoids which are otherwise sensitive to light. Some drawbacks have been reported for this traditional drying method. Among others it does not achieve the high quality standards required for medicinal plants (Rocha et al., 2011). Nonetheless the method is a suitable drying procedure for herbs dried in small quantities in usua domestic conditions.

Regarding the microwave drying it is obvious that this method significantly reduces the overall drying time in comparison with other methods, but drying parameters such as microwave power and drying intervals must be set carefully. Our results showed promising results in terms of preservation of studied pigments content when short time intervals with high power were used. However, it is worth mentioning that the using of a microwave oven does not ensure reproducibility of heating regime very reliably because of dependence on construction, geometry and temperature profile development, even if the same power is set up. Therefore, in the case of using the MW method the parameters should be re-configured for specific technical device to minimize the losses of qualitative properties of dried herbs. The method is feasible for domestic conditions as well as in a larger scale of production. In mass production, the drawbacks of microwave drying are, besides already mentioned non-uniformity of heating, the operational costs and the difficulty to control the final product temperature (Zhang et al., 2006). On the other hand, improvement in product quality is considered to be the foremost benefit of this drying method (Feng $\boldsymbol{e}$ al., 2012). However, productivity of this drying process still remains questionable since the drying must be conducted in thin leaf layers and humidity removal has to be resolved.

When we dried the leaves in an oven (CD) we reduced the temperature to $25^{\circ} \mathrm{C}$ to avoid loss of quality of dried herbs caused by higher temperature (DiazMaroto et al., 2002) though it has been previously documented that the drying air temperatures between 50 and $60{ }^{\circ} \mathrm{C}$ appear as feasible for drying of large numbers of medicinal plants (Rocha et al., 2011). Our results confirmed presence of pigments in leaves of herbs dried by CD method and as can be seen in Table 2 the statistical significant differences were observed just in some cases. The convective oven drying is the most popular method of herb drying and it is generally recommended as a more suitable method then air drying (Oztekin and Martinov, 2007). The data obtained in our work support the suggestion that the convective oven drying is suitable for domestic use and can be used for large production, as well.

\section{CONCLUSION}

The results presented in this study provide insight into the effect of drying procedures on content of chlorophyll $a$, chlorophyll $b$ and carotenoids in two traditionally used herbs Melissa officinalis L. and Urtica dioica L. under laboratory conditions. We can conclude that while microwave and air drying with sun exposure better preserve the pigments in $M$. officinalis, in $U$. dioica the air drying with sun exposure seems to be the more efficient dehydration method. All drying methods used in this study are feasible under domestic conditions and the suggested parameters of drying could also be applied in a large scale of production with the exception of microwave drying where working parameters must be adapted to a specific technical device.

Acknowledgments: This work was supported by Scientific Grant Agency (VEGA Project \#1/0765/14), Research and Development Support Agency (APVV Project \#0202-10), Grant Agency of Constantine Philosopher University in Nitra (UGA Project \#VII/6/2014), and European Community (Building Research Centre „AgroBioTech" Project \#26220220180). The authors thank Michael Lawson for spelling and grammar corrections.

\section{REFERENCES}

ABASCAL, K., GANORA, L., YARNELL, E. 2005. The effect of freeze-drying and its implications for botanical medicine: a review. Phytotherapy Research, 19(8), 655-660. http://dx.doi.org/10.1002/ptr.1651

DERMELJ, M., BOGENRIEDER, C., HÍDVÉGI, M., LÁSZTITY, R. 1995 Effect of microwave vacuum drying on protein and chlorophyll contents of blind nettle (Urtica urens L.) Periodica Polytechnica Chemical Engineering, 39(1), 77 84.

DÍAZ-MAROTO, M.C., PÉREZ-COELLO, M.S., CABEZUDO, M.D. 2002 Effect of different drying methods on the volatile components of parsley (Petroselinum crispum L.) European Food Research and Technology, 215, 227230. http://dx.doi.org/10.1007/s00217-002-0529-7

DIV YA, P., PUTHUSSERI, B., NEELWARNE, B. 2012. Carotenoid content, its stability during drying and the antioxidant activity of commercial coriander (Coriandrum sativum L.) varieties Food Research International. 45(1), 342-350. http://dx.doi.org/10.1016/j.foodres.2011.09.021

FENG, H., YIN, Y., TANG, J. 2012. Microwave drying of food and agricultural materials: basics and heat and mass transfer modeling. Food Engineering Reviews, 4(2), 89-106. http://dx.doi:10.1007/s12393-012-9048-x

GUIL-GUERRERO J.L., REBOLLOSO-FUENTES, M.M, TORIJA ISASA M.E. 2003. Fatty acids and carotenoids from Stinging Nettle (Urticadioica L.) Journal of Food Composition and Analysis, 16(2), 111-119. http://dx.doi.org/10.1016/s0889-1575(02)00172-2

HOJNIK M., ŠKERGET, M., KNEZ, Ž. 2007. Isolation of chlorophylls from stinging nettle (Urtica dioica L.). Separation and purification technology, 57(1), 37- 46. http://dx.doi.org/10.1016/j.seppur.2007.02.018

KAMEL, M.S., THABET, A.H., ALGADI, A. E. 2013. Influence of Drying Process on the Functional Properties of Some Plants. Chemistry and Materials Research, 3(7), 1-8.

KOCA, N., BURDURLU, H.S., KARADENIZ, F. 2007. Kinetics of colour changes in dehydrated carrots. Journal of Food Engineering, 78(2), 449-455 http://dx.doi.org/10.1016/j.jfoodeng.2005.10.014

KOMES, D., BELŠČCAK-CVITANOVIĆ, A., HORŽIĆ, D., MARKOVIĆ, K. KOVAČEVIĆ GANIĆ K. 2011. Characterisation of pigments and antioxidan properties of three medicinal plants dried under different drying conditions. 11th International Congress on Engineering and Food "Food Process Engineering in a Changing World" May 22-26. Athens, Greece

MUDAU, F.N., NGEZIMANA, W. 2014. Effect of different drying methods on chemical composition and antimicrobial activity of bush tea

(Athrixia phylicoides). International Journal of Agriculture and Biology, 16(5), 1011-1014.

NIJHUIS, H. H., TORRINGA, H. M., MURESAN, S., YUKSEL, D., LEGUIJT,

C., KLOEK, W. (1998). Approaches to improving the quality of dried fruit and 
vegetables. Trends in Food Science and Technology, 9(1), 13-20. http://dx.doi.org/10.1016/s0924-2244(97)00007-1

ORPHANIDES, A., GOULAS, V., GEKAS, V. 2013. Effect of drying method on the phenolic content and antioxidant capacity of spearmint. Czech Journal of Food Sciences, 31, 509-513.

PURANIK, V., CHAUHAN, D.K., MISHRA, V., RAI, G.K. 2012. Effect of drying techniques on the physicochemical and bioactive components of selected medical herbs. Annals of Phytomedicine, 1(2), 23-29.

ROCHA, R. P., MELO, E. C., RADÜNZ L. L. 2011. Influence of drying process on the quality of medicinal plants: A review. Journal of Medicinal Plants Research, 5(33), 7076-7084. http://dx.doi.org/10.5897/jmprx11.001

ROCK, CH. L. 2003. Diet and Breast Cancer: Can Dietary Factors Influence Survival? Journal of Mammary Gland Biology and Neoplasia, 8 (1), 119-132. http://dx.doi.org/10.1023/a:1025791523375

SHARAFZADEH, S., ALIZADEH, O. 2011. Chlorophyll $a$, Chlorophyll $b$ and Carotenoids of Garden Thyme (Thymus vulgaris L.). as Affected by Nutrients. Advances in Environmental Biology, 5(12), 3725-3728.

YANG, C.M., CHANG, K.W., YIN, M.H., HUANG, H.M. 1998. Methods for the determination of the chlorophylls and their derivatives. Taiwania, 43(2), 116122.

ZHANG, M., TANG. J., MUJUMDAR, A. S., WANG, S. 2006. Trends in microwave-related drying of fruits and vegetables. Trends in Food Science and Technology, 17(10), 524-534. http://dx.doi:10.1016/j.tifs.2006.04.011 